\title{
Effect of Different Methods of Reperfusion on Short-Term Outcomes in Patients with Acute Inferior S-T Segment Elevation Myocardial Infarction Associated with Ischemic Mitral Regurge
}

\author{
Mohey Mansour El-Abbady, Mohammed Usama Taha, Mohammed Saeed Al-shorbagy, \\ Ibrahim Abdelfattah Yassin, Haitham Alshahat Ramadan
}

Department of Cardiology, Al-Azhar Faculty of Medicine, Al-Azhar University and National heart institute, Egypt Corresponding author: Dr. Haitham Ramadan,National heart institute,Tel: 00201116671227

email:drhaithamramadan@gmail.com

\begin{abstract}
Background: Follow-up of patients with inferior STEMI having acute significant mitral regurgitation to assess the effect of mitral regurgitation and the type of reperfusion therapy whether thrombolytic therapy or PCI on the prognosis of these patients

Patients and methods: This is a prospective, observational, non-controlled study included two hundred and forty patients with inferior STEMI admitted at National Heart Institute from august 2016 to August 2018. The patients were classified into 2 groups according to presence or absence of mitral regurgitation, 120 patients in each group. Group A (ischemic MR) was further subdivided into 2 subgroups, 60 patients who underwent primary PCI and 60 patients who received thrombolytic therapy.

Results: Patients presenting with inferior STEMI and having ischemic mitral regurgitation (IMR) had more, in hospital, complications regarding life threatening arrhythmias, cardiogenic shock and mortality. On three months follow-up these patients had more incidence of developing congestive heart failure and low ejection fraction. On analyzing the data of each subgroup, the patients who had IMR and received thrombolytic therapy had more sever mitral regurgitation, more in-hospital complications and more incidence of congestive heart failure than those patients who had IMR but underwent primary PCI.

Conclusion: Patients with inferior STEMI and having IMR are at more risk for developing in hospital complications and have higher incidence to develop congestive heart failure. However, in these patients those who underwent primary PCI have much better prognosis than those who received thrombolytic therapy.
\end{abstract}

Keywords: Inferior STEMI, Ischemic Mitral Regurgitation, Primary PCI.

\section{INTRODUCTION}

Ischemic coronary insufficiency (IMR) is coronary insufficiency caused by coronary artery disease in the absence of internal valve lesions, which are common complications of acute myocardial infarction (AMI) ${ }^{(1)}$ that is occurring in $15-64 \%$ of patients after the event, which is independent indicator of future cardiovascular mortality ${ }^{(2)}$.

During AMI, mitral regurgitation carries an adverse prognosis and it has been associated with high mortality (3). The presence and degree of IMR are associated with lower long-term survival in patients after a first non-ST-segment elevation acute coronary syndrome ${ }^{(4)}$.

Mild and moderate functional mitral insufficiency lead to a worse prognosis in patients undergoing coronary artery bypass grafting (CABG) ${ }^{(5)}$.

In addition, IMR severity is positively associated with development of heart failure after AMI (6). Because of its complex pathophysiology and heterogeneous clinical presentation. The proper treatment of ischemic MR is often debated, and the relative utility of revascularization with and without concomitant mitral valve surgery is uncertain ${ }^{(7)}$. Although primary percutaneous coronary intervention (PCI) for AMI is known to improve outcome ${ }^{(8)}$, and that IMR after myocardial infarction (MI) worsens outcome ${ }^{(9)}$. The effect of primary PCI on IMR incidence has not been specifically studied.

\section{PATIENTS AND METHODS}

\section{Study design:}

This is a prospective, observational, noncontrolled study that was performed from august 2016 to August 2018 and included 240 patients presented to the emergency department of the National Heart Institute for the first time with acute inferior ST segment elevation myocardial infarction according to the third universal definition of myocardial infarction. Thygesen et al. ${ }^{(10)}$ which requires the presence of typical chest pain lasting for more than 30 min with ST-segment elevation $>1 \mathrm{~mm}$ in 2 of the inferior leads. The patients were divided into two groups. Group A: included 120 patients with ischemic mitral regurgitation, this group was divided into 2 subgroups: Subgroup I: included 60 patients that were treated by primary PCI and Subgroup II: included 60 patients that were treated by thrombolytic therapy. Group B: included 120 patients of matching age, sex and risk factors without ischemic mitral regurgitation that were treated with either primary PCI or thrombolytic. The study was approved by the Ethics Board of AlAzhar University and an informed written consent was taken from each participant in the study. 


\section{Baseline evaluation:}

All patients had review of their medical history on admission to emergency department including analysis of demographic data (age, sex), presence of risk factors of coronary atherosclerosis, associated comorbidities, general and cardiac examination and 12 leads ECG which was performed immediately on admission and every $6 \mathrm{~h}$ during the first $24 \mathrm{~h}$, and once daily until discharge. Routine laboratory investigations including cardiac biomarkers (Troponin I \& CK-MB). Echocardiographic assessment was performed to all patients on admission, then repeated before discharge and at 3 months follow-up.

\section{Treatment:}

Reperfusion therapy was done using Primary PCI for subgroups I, or streptokinase 1.500 .000 international units intravenous infusion along one hour for subgroups II.

All patients received the standard anti-ischemic treatment during emergency and hospital stay.

\section{Coronary angiography:}

Informed written consent was obtained for all patients. The procedure was done according to the standard technique for coronary angiography. Tran femoral approach was done in all patients using seldinger technique.

\section{Follow up:}

All patients were followed during hospital stay and for 3 months after discharge for mortality and morbidity (arrhythmia, HF, angina. etc) in each group.

\section{Statistical analysis}

Data are presented as mean \pm SD for continuous data and as number (\%) for categorical data. Between groups, analysis was done using student t-test for continuous data and Chi-square test (or Fischer exact test) for qualitative data. Level of evidence was detected to be significant at $\mathrm{P}$ value $<0.05$.

\section{RESULTS}

\section{Study population}

The total number of patients included in the study was 240 patients. They were 153 males $(63.7 \%)$ and 87 females $(36.3 \%)$. In group A (patients with mitral regurgitation) there were 80 males $(66.6 \%)$ and 40 females (33.4\%), in group B (patients without mitral regurgitation) there were 72 males $(60.0 \%)$ and 48 female $(40 \%)$.

The mean age was $65.48 \pm 10.49$ years in group A and $63.12 \pm 9.83$ years in group B.

Diabetic patients were $136(56.6 \%) ; 73(60.8 \%)$ in group A and 63(52.5\%) in group B.

Hypertensive patients were 134 (55.8\%); $62(51.6 \%)$ in group A and 72 (60.0\%)in group B.

The number of smokers in total population was 144 (60.0\%); they were $69(57.5 \%)$ in group A and 75 $(62.5 \%)$ in group B.

The total number of patients with positive family history for CAD was $143(59.5 \%)$, in group A they were $73(60.8 \%)$ and in group B they were $70(58.7 \%)$. All the aforementioned data are available in table (1).

Table (1): Demographic data and distribution of patients according to coronary risk factors $(\mathrm{N}=240)$

\begin{tabular}{|c|c|c|c|c|c|}
\hline & & $\begin{array}{c}\text { Total population } \\
\mathrm{N}=240\end{array}$ & $\begin{array}{c}\text { Group A } \\
\mathrm{N}=120\end{array}$ & $\begin{array}{c}\text { Group B } \\
\mathrm{N}=120\end{array}$ & P value \\
\hline Age & $($ mean \pm SD) & $63.31 \pm 12.36$ & $65.48 \pm 10.49$ & $63.12 \pm 9.83$ & 0.809 \\
\hline Male gender & (No. \&\%) & $153(63.7 \%)$ & $80(66.6 \%)$ & $72(60.0 \%)$ & 0.738 \\
\hline DM & $($ No. \& \%) & $136(56.6 \%)$ & $73(60.8 \%)$ & $63(52.5 \%)$ & 0.405 \\
\hline HTN & $($ No. \& \%) & $134(55.8 \%)$ & $62(51.6 \%)$ & $72(60.0 \%)$ & 0.102 \\
\hline Smoking & $($ No. \& \%) & $144(60.0 \%)$ & $69(57.5 \%)$ & $75(62.5 \%)$ & 0.551 \\
\hline FH & (No. \& \%) & $143(59.5 \%)$ & $73(60.8 \%)$ & $70(58.7 \%)$ & 0.795 \\
\hline
\end{tabular}

$\mathrm{SD}=$ standard deviation, $\mathrm{DM}=$ diabetes mellitus, $\mathrm{HTN}=$ hypertension, $\mathrm{FH}=$ family history.

\section{Admission clinical and Laboratory characteristics (table 2):}

Chest pain was present in all patients at presentation (100\% for both group). The mean HR was $79.83 \pm 18.06$ $\mathrm{b} / \mathrm{min}$ in group A patients and $81.17 \pm 17.26 \mathrm{~b} / \mathrm{min}$ in group B patients.

The mean SBP was $126.21 \pm 26.06 \mathrm{mmHg}$ in group A patients and $127.33 \pm 25.57 \mathrm{mmHg}$ in group B.

The mean DBP was $73.67 \pm 18.09 \mathrm{~mm} \mathrm{Hg}$ in group A patients and, $74.67 \pm 19.09$ in group B patients.

All patients in the study had elevated CK-MB, with mean CK-MB $72.68 \pm 25.61 \mathrm{mg} / \mathrm{dl}$ in group A and $70.43 \pm$ $28.72 \mathrm{mg} / \mathrm{dl}$ in group B.

The mean serum creatinine was $1.2 \pm 0.34 \mathrm{mg}$ in group A and $1.04 \pm 0.28 \mathrm{mg}$ in group B.

The mean random blood glucose was $213.53 \pm 83.59 \mathrm{mg} / \mathrm{dl}$ in group A and $200.92 \pm 85.94 \mathrm{mg} / \mathrm{dl}$ in group B. 
Table (2): Admission clinical and Laboratory characteristics ( $N=240)$

\begin{tabular}{|c|c|c|c|c|}
\hline & $\begin{array}{l}\text { Total } \\
\text { population } \\
\mathbf{N}=\mathbf{2 4 0}\end{array}$ & $\begin{array}{l}\text { Group A } \\
\mathbf{N}=\mathbf{1 2 0}\end{array}$ & $\begin{array}{l}\text { Group B } \\
\mathbf{N}=120\end{array}$ & P-value \\
\hline $\begin{array}{l}\text { Chest pain } \\
(\text { No \& \%) }\end{array}$ & $240(100 \%)$ & $120(100 \%)$ & $120(100 \%)$ & 1 \\
\hline $\begin{array}{l}\text { HR } \\
(\text { mean } \pm \text { SD) }\end{array}$ & $80.86 \pm 19.23$ & $79.83 \pm 18.06$ & $81.17 \pm 17.26$ & 0.680 \\
\hline $\begin{array}{l}\text { SBP } \\
(\text { mean } \pm \text { SD) }\end{array}$ & $\begin{array}{l}126.89 \pm \\
28.87 \\
\end{array}$ & $\begin{array}{l}126.21 \pm \\
26.06\end{array}$ & $\begin{array}{l}127.33 \pm \\
25.57 \\
\end{array}$ & 0.844 \\
\hline $\begin{array}{l}\begin{array}{l}\text { DBP } \\
(\text { mean } \pm \text { SD })\end{array} \\
\end{array}$ & $72.87 \pm 22.45$ & $73.67 \pm 18.09$ & $70.43 \pm 28.72$ & 0.903 \\
\hline $\begin{array}{l}\begin{array}{l}\text { CK-MB } \\
(\text { mean } \pm \text { SD })\end{array} \\
\end{array}$ & $71.96 \pm 27.71$ & $72.68 \pm 25.61$ & $70.43 \pm 28.72$ & 0.923 \\
\hline $\begin{array}{l}\text { Serum creat. } \\
(\text { mean } \pm \text { SD })\end{array}$ & $1.1 \pm 0.16$ & $1.2 \pm 0.14$ & $1.04 \pm 0.18$ & 0.815 \\
\hline $\begin{array}{l}\text { RBG } \\
(\text { mean } \pm \text { SD })\end{array}$ & $210.65 \pm 45$ & $\begin{array}{l}213.53 \pm \\
83.59\end{array}$ & $\begin{array}{l}200.92 \pm \\
85.94\end{array}$ & 0.758 \\
\hline
\end{tabular}

$\mathrm{HR}=$ heart rate, $\mathrm{SBP}=$ systolic blood pressure, $\mathrm{DBP}=$ diastolic blood pressure, $\mathrm{RBG}=$ random blood glucose.

This table showed that there was no statistically significant difference between the 2 groups regarding the clinical and laboratory findings on admission.

Baseline and follow-up echocardiographic data (tables 4, 5 and 6):

The LVESD on admission was $38.23 \pm 7.6$ in group A versus $34.19 \pm 5.3$ in group B (P-value was 0.083 ), before discharge it was $41.54 \pm 9.7$ in group A versus $36.21 \pm 3.6$ in group B (P-value was 0.037) and at 3 months follow-up it was $50.31 \pm 8.7$ in group A versus $40.12 \pm 1.1$ in group B (P-value was $<0.001)$. The LVEDD on admission was $51.65 \pm 6.7$ in group A versus $48.78 \pm 4.5$ in group B (P-value was 0.087 ), before discharge it was $53.65 \pm 6.8$ in group A versus $50.63 \pm 4.7$ in group B (P-value was 0.034 ) and at 3 months follow-up it was $57.98 \pm 1.9$ in group A versus $51.23 \pm 5.6$ in group B ( $\mathrm{P}$-value was $<0.001)$.

Ejection fraction on admission was $48.77 \pm 7.75$ in group A versus $50.23 \pm 6.58$ in group B (P-value was 0.076 ), before discharge $\mathrm{EF}$ was $49.64 \pm 8.20$ in group A versus 55.72 \pm 6.45 in group B (P-value was 0.021), at 3 months follow-up, EF was $50.48 \pm 7.07$ in group $\mathrm{A}$ versus $57.08 \pm 6.14$ in group B (P-value was < 0.001 ). Wall motion score index on admission was $1.75 \pm 0.24$ in group A versus $1.72 \pm 0.35$ in group B (P-value was $0.724)$, before discharge WMSI was $1.69 \pm 0.52$ in group A versus $1.63 \pm 0.39$ in group B (P-value was 0.027 ), on 3 months follow-up, it was $1.67 \pm 0.52$ in group A versus $1.59 \pm 0.28$ in group B (P-value was < $0.001)$.

Table (3): Baseline echocardiographic data $(\mathrm{N}=240)$

\begin{tabular}{|l|l|l|l|}
\hline & $\begin{array}{l}\text { Group A } \\
\text { N=120 }\end{array}$ & $\begin{array}{l}\text { Group B } \\
\text { N=120 }\end{array}$ & P-value \\
\hline $\begin{array}{l}\text { LVESD } \\
(\text { mean } \pm \text { SD) }\end{array}$ & $38.23 \pm 7.6$ & $34.19 \pm 5.3$ & 0.083 \\
\hline $\begin{array}{l}\text { LVEDD } \\
(\text { mean } \pm \text { SD) }\end{array}$ & $51.65 \pm 6.7$ & $48.78 \pm 4.5$ & 0.087 \\
\hline $\begin{array}{l}\text { EF } \\
(\text { \%ean } \pm \text { SD) }\end{array}$ & $48.77 \pm 7.75$ & $50.23 \pm 6.58$ & 0.076 \\
\hline $\begin{array}{l}\text { WMSI } \\
(\text { mean } \pm \text { SD) }\end{array}$ & $1.75 \pm 0.24$ & $1.72 \pm 0.35$ & 0.724 \\
\hline
\end{tabular}

LVESD = left ventricular end systolic dimension, LVEDD = left ventricular end diastolic dimension, EF = ejection fraction, WMSI = wall motion scone index. 
Table (4): Echocardiographic data before discharge (N=232)

\begin{tabular}{|c|c|c|c|}
\hline & $\begin{array}{c}\text { Group A } \\
\text { N= 114 }\end{array}$ & $\begin{array}{c}\text { Group B } \\
\text { N=118 }\end{array}$ & P-value \\
\hline $\begin{array}{c}\text { LVESD } \\
(\text { mean } \pm \text { SD })\end{array}$ & $41.54 \pm 9.7$ & $36.21 \pm 3.6$ & 0.037 \\
\hline $\begin{array}{c}\text { LVEDD } \\
(\text { mean } \pm \text { SD })\end{array}$ & $53.65 \pm 6.8$ & $50.63 \pm 4.7$ & 0.034 \\
\hline $\begin{array}{c}\text { EF } \\
(\text { mean } \pm \text { SD })\end{array}$ & $49.64 \pm 8.20$ & $55.72 \pm 6.45$ & 0.021 \\
\hline $\begin{array}{c}\text { WMSI } \\
(\text { mean } \pm \text { SD })\end{array}$ & $1.69 \pm 0.52$ & $1.63 \pm 0.39$ & 0.027 \\
\hline
\end{tabular}

LVESD = left ventricular end systolic dimension, LVEDD = left ventricular end diastolic dimension, $\mathrm{EF}=$ ejection fraction, WMSI = wall motion scone index .

Table (5): Echocardiographic data at 3 months follow-up (N=221)

\begin{tabular}{|c|c|c|c|}
\hline & $\begin{array}{c}\text { Group A } \\
\text { N=105 }\end{array}$ & $\begin{array}{c}\text { Group B } \\
\text { N=116 }\end{array}$ & P-value \\
\hline LVESD $_{3}($ mean \pm SD) & $50.31 \pm 8.7$ & $40.12 \pm 1.1$ & $<0.001$ \\
\hline LVEDD $_{3}($ mean \pm SD) & $57.98 \pm 1.9$ & $\mathbf{5 1 . 2 3} \pm 5.6$ & $<0.001$ \\
\hline EF $_{3} \%($ mean \pm SD) & $50.48 \pm 7.07$ & $\mathbf{5 7 . 0 8} \pm 6.14$ & $<0.001$ \\
\hline WMSI $_{3}($ mean \pm SD) & $1.67 \pm 0.52$ & $\mathbf{1 . 5 9} \pm \mathbf{0 . 2 8}$ & $<0.001$ \\
\hline
\end{tabular}

LVESD = left ventricular end systolic dimension, LVEDD = left ventricular end diastolic dimension, EF = ejection fraction, WMSI = wall motion scone index .

\section{Clinical outcome among the total population during} 3 months follow-up:

Re infarction was recorded in 2 patients in both groups (P-value was 1).

Ventricular Fibrillation was recorded in $\mathbf{7}$ patients in group A versus 4 patients in group B (P-value was $0.618)$.

Complete heart block was recorded in $\mathbf{6}$ patients in group A versus 4 patients in group B (P-value was $0.927)$.
Major bleeding was observed in $\mathbf{4}$ patients in group A versus 2 patient in group B (P-value was 0.735).

Cardiogenic shock was recorded in $\mathbf{1 1}$ patients in group A versus 8 patients in group B (P-value was 0.509 ).

Heart failure was observed in 21 patients in group A versus 6 patients in group B, this difference was statistically significant $(\mathrm{P}$-value $<0.05)$.

Mortality rate was significantly higher in group A with 15 patients versus 4 patients in group B (P-value $<0.05$ ) (Figure 1).

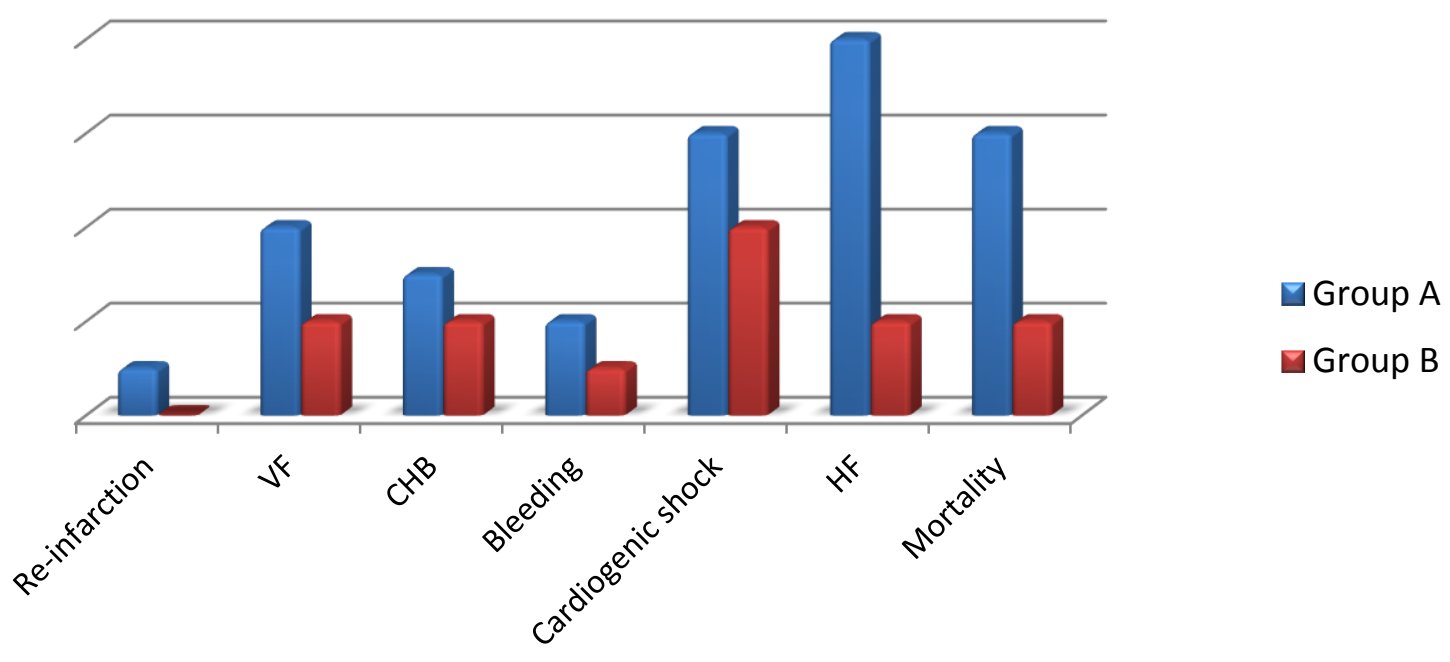

Figure (1): Clinical outcome among the studied population. 


\section{Subgroup analysis in group $A$}

Demographic and coronary risk factors data among patients with ischemic mitral regurgitation, Figure (2):

The total number of patients with mitral regurgitation was 120 patients, their mean age was $64.17 \pm 11.67$ years in subgroup AI (mitral regurgitation treated by $\mathbf{P C I}$ ) and $66.80 \pm 9.36$ in subgroup AII (mitral regurgitation treated by thrombolytic therapy) $(\mathrm{P}=0.817)$.

In subgroup AI there were 43 (71.6\%) male patients versus 38(63.3\%) male patients in subgroup AII (P-value was 0.781).

In subgroup AI there were 37 (61.6\%) diabetic patients versus $36(60.0 \%)$ diabetic patients in subgroup AII (P-value was 0.598)

There were $33(55 \%)$ hypertensive patients in subgroup AI versus 29 (48.3\%) hypertensive patients in subgroup AII (P-value was 0.795).

Smokers were 35 (58.5\%) patients in subgroup AI versus $35(58.5 \%)$ patients in subgroup AII (P-value was 1$)$. Positive family history for coronary artery disease was recorded in $37(61.6 \%)$ patients in subgroup AI versus 33 (55\%) patients in subgroup AII (P-value was 0.636).

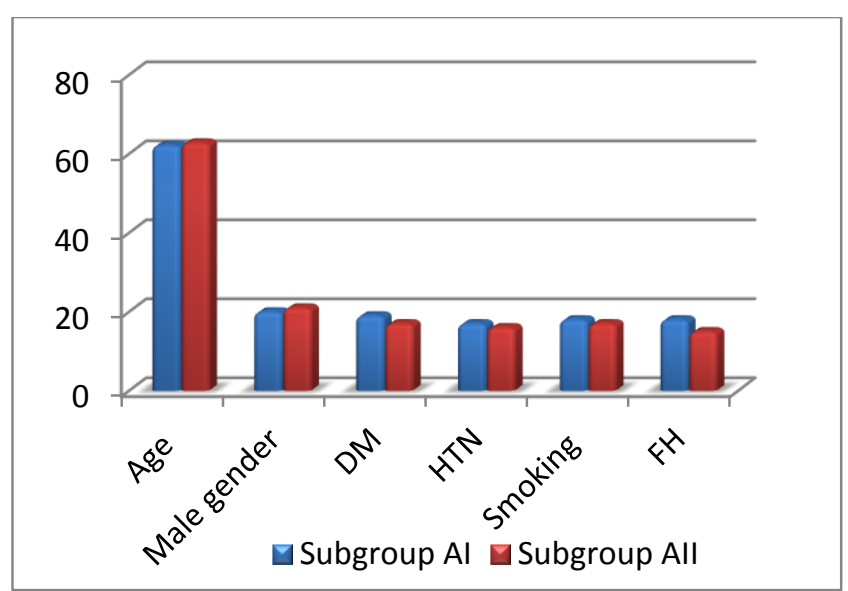

Figure (2): Demographic and coronary risk factors among patients with ischemic mitral regurgitation

Baseline and follow-up echocardiographic data among patients with ischemic mitral regurgitation: In subgroup AI, the mitral regurgitation jet area remarkably decreased from baseline $5.27 \pm 2.32 \mathrm{~cm}^{2}$ to $3.48 \pm 2.40 \mathrm{~cm}^{2}$ before discharge and then to $2.18 \pm$ $1.39 \mathrm{~cm}^{2}$ at 3 months follow-up echocardiography. In subgroup AII jet area was $5.90 \pm 2.23 \mathrm{~cm}^{2}$ on admission then $4.76 \pm 2.26 \mathrm{~cm}^{2}$ before discharge and $4.31 \pm 1.95$ $\mathrm{cm}^{2}$ at 3 months follow-up echocardiography. There was no statistically significant difference between the two groups regarding jet area on admission. However these differences increased to become statistically significantly before discharge and at 3 months followup echocardiography (P-value < 0.001) (Table 6).
Table (6): Evaluation of jet area on admission and during follow-up in patients with ischemic mitral regurgitation $(\mathrm{N}=120)$ :

\begin{tabular}{|c|c|c|c|}
\hline & $\begin{array}{c}\text { Subgroup AI } \\
\mathrm{N}=60\end{array}$ & $\begin{array}{c}\text { Subgroup AII } \\
\mathrm{N}=60\end{array}$ & P-value \\
\hline $\begin{array}{l}\text { Jet area } \mathrm{cm}^{2} \\
(\text { mean } \pm \mathrm{SD})\end{array}$ & $5.27 \pm 2.32$ & $5.90 \pm 2.23$ & 0.926 \\
\hline $\begin{array}{l}\text { Jet area } \mathrm{cm}^{2} \\
(\mathrm{mean} \pm \mathrm{SD})\end{array}$ & $3.48 \pm 2.40$ & $4.76 \pm 2.26$ & 0.042 \\
\hline $\begin{array}{l}\text { Jet area } \mathrm{cm}^{2} \\
(\text { mean } \pm \mathrm{SD})\end{array}$ & $2.18 \pm 1.39$ & $4.31 \pm 1.95$ & $<0.001$ \\
\hline
\end{tabular}

(1) = on admission echo, (2) = before discharge echo, (3) $=$ at 3 months follow-up echo.

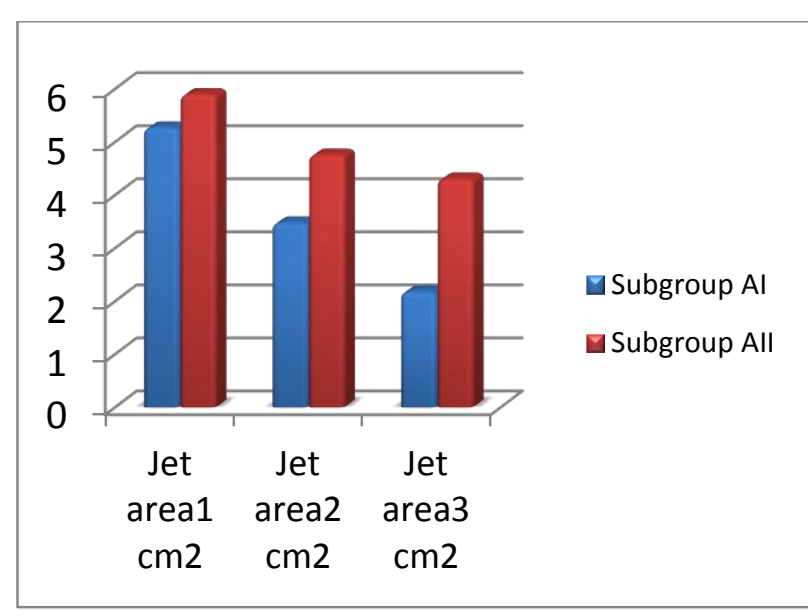

Figure (3): Evaluation of jet area on admission and during follow-up in patients with ischemic mitral regurgitation

Ejection fraction was remarkably increased in subgroup AI from baseline of $47.43 \pm 6.75$, to $51.10 \pm$ 7.02 before discharge and to $56.46 \pm 6.85$ at the 3 months follow-up echocardiography. While, in subgroup AII the EF increased less significantly from baseline of $47.53 \pm 8.76$, to $49.17 \pm 9.33$ before discharge and then to $50.42 \pm 7.28$. The difference was not significant between the 2 subgroups on admission, but it become statistically significant on the follow-up echocardiography (p-value < 0.005) (Table 7).

Table (7): Evaluation of EF on admission and during follow-up in patients with ischemic mitral regurgitation $(\mathrm{N}=120)$ :

\begin{tabular}{|c|c|c|c|}
\hline & $\begin{array}{c}\text { Subgroup AI } \\
\text { N=60 }\end{array}$ & $\begin{array}{c}\text { Subgroup AII } \\
\text { N=60 }\end{array}$ & P-value \\
\hline $\begin{array}{c}\mathrm{EF}_{1} \\
(\text { mean } \pm \mathrm{SD})\end{array}$ & $47.43 \pm 6.75$ & ff $47.53 \pm 8.76$ & 0.961 \\
\hline $\begin{array}{c}\mathrm{EF}_{2} \\
(\text { mean } \pm \mathrm{SD})\end{array}$ & $51.10 \pm 7.02$ & $49.17 \pm 9.33$ & 0.033 \\
\hline $\begin{array}{c}\mathrm{EF} \\
(\text { mean } \pm \mathrm{SD})\end{array}$ & $56.46 \pm 6.85$ & $50.42 \pm 7.28$ & 0.020 \\
\hline
\end{tabular}

$\mathrm{EF}=$ ejection fraction, $(1)=$ on admission echo, $(2)=$ before discharge echo, (3) = at 3 months follow-up echo. 


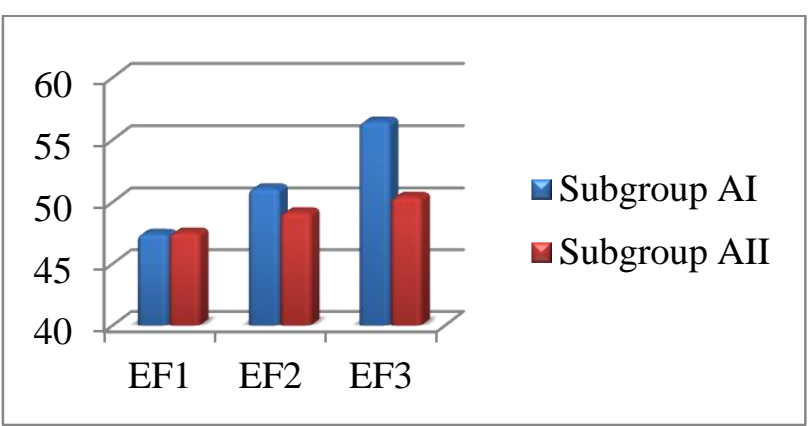

Figure (4): Evaluation of EF on admission and during follow-up of patients with ischemic mitral regurgitation

In subgroup AI the WMSI decreased from 1.74 \pm 0.25 in the baseline echocardiography to $1.62 \pm 0.23$ before discharge and to $1.54 \pm 0.46$ at 3 months followup echocardiography. In subgroup AII, it decreased less obviously from $1.73 \pm 0.34$ at baseline echocardiography to $1.66 \pm 0.59$ before discharge then to $1.62 \pm 0.68$. The difference between the 2 groups was statistically significant before discharge and in the follow-up echocardiography 3 months later (P-value < 0.005) (table 12).

Table (8): Evaluation of WMSI on admission and during follow-up in patients with ischemic mitral regurgitation $(\mathrm{N}=120)$ :

\begin{tabular}{|c|c|c|c|}
\hline & $\begin{array}{c}\text { Subgroup AI } \\
\mathrm{N}=60\end{array}$ & $\begin{array}{c}\text { Subgroup AII } \\
\mathrm{N}=60\end{array}$ & P-value \\
\hline $\begin{array}{c}\mathrm{WMSI}_{1} \\
(\mathrm{mean} \pm \mathrm{SD})\end{array}$ & $1.74 \pm 0.25$ & $1.73 \pm 0.34$ & 0.857 \\
\hline $\begin{array}{c}\mathrm{WMSI}_{2} \\
(\text { mean } \pm \mathrm{SD})\end{array}$ & $1.62 \pm 0.23$ & $1.66 \pm 0.59$ & 0.021 \\
\hline $\begin{array}{c}\mathrm{WMSI}_{3} \\
(\text { mean } \pm \mathrm{SD})\end{array}$ & to $1.54 \pm 0.46$ & to $1.62 \pm 0.68$ & $<0.001$ \\
\hline
\end{tabular}

WMSI = wall motion score index, $(1)=$ on admission echo, (2) = before discharge echo, (3) = at 3 months follow-up echo.

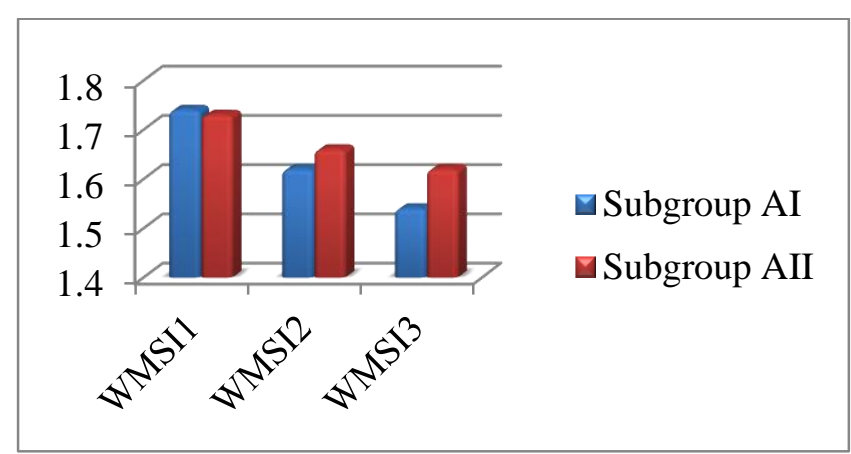

Figure (5): Evaluation of WMSI on admission and during follow-up in patients with ischemic mitral regurgitation

\section{Clinical outcome in patients with ischemic mitral regurgitation:}

-There was no evidence of reinfarction in subgroup AI while 2 patients with reinfarction was recorded in subgroup AII (P-value was 0.754).

Ventricular Fibrillation was recorded in $\mathbf{4}$ patients in both subgroups (P-value was 1).

Complete heart block was recorded in $\mathbf{4}$ patients in subgroup AI versus 2 patients in group AII (P-value was 0.369).

-Bleeding was observed in 2 patients in each subgroup (P-value was 1).

-Cardiogenic shock was recorded in $\mathbf{4}$ patients in subgroup AI versus 7 patients in subgroup AII (P-value was 0.509).

-Heart failure was observed in 6 patients in subgroup AI versus 15 patients in subgroup AII, this difference was statistically significant (P-value $<0.05$ ).

Mortality rate was 6 patients in subgroup AI versus 9 patients in subgroup AI (P-value was 0.619).

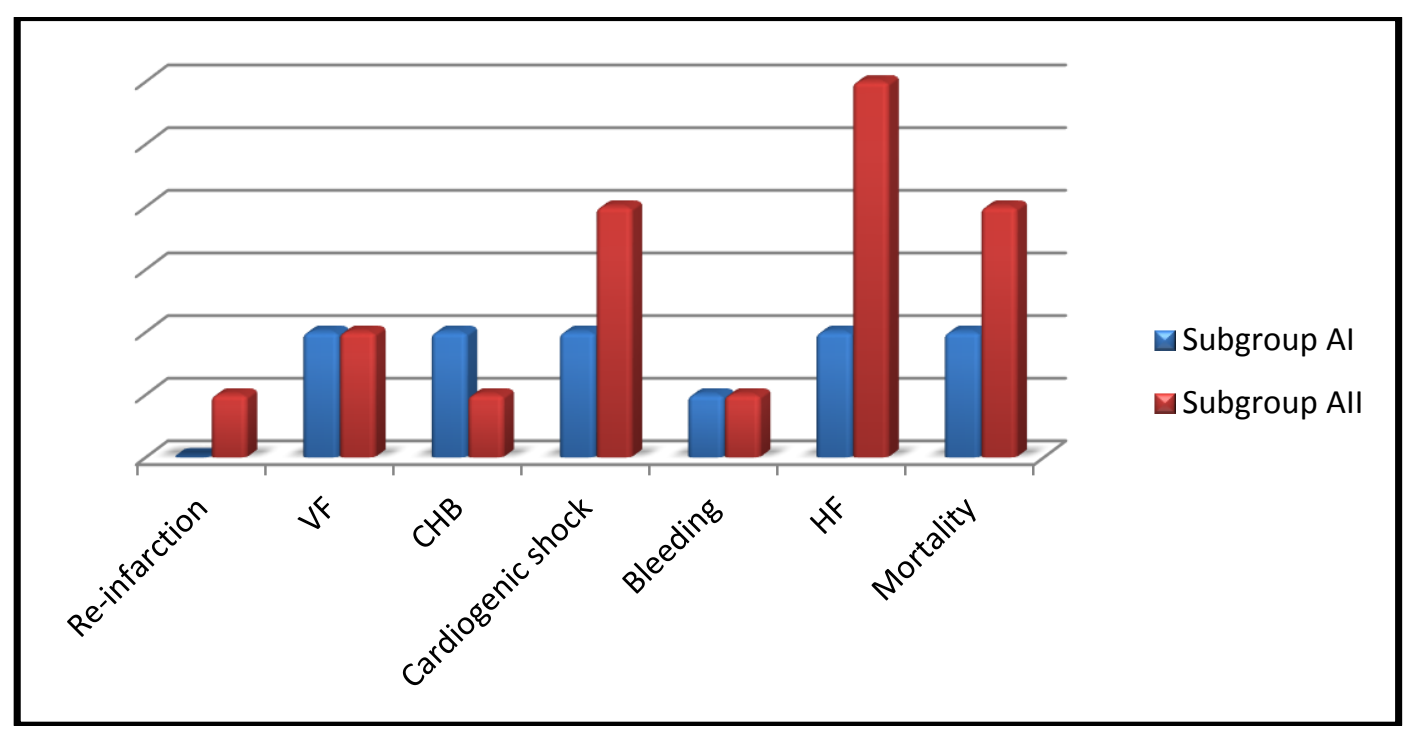

Figure (6): Clinical outcome among patients with ischemic mitral regurgitation 


\section{Correlation between number of diseased vessels and development of mitral regurgitation:}

The extent of coronary artery disease was significantly higher in subgroup AI (mitral regurgitation treated by PCI) than subgroup B (no mitral regurgitation treated by $\mathrm{PCI}$ ( $\mathrm{P}$-value was 0.035$)$.

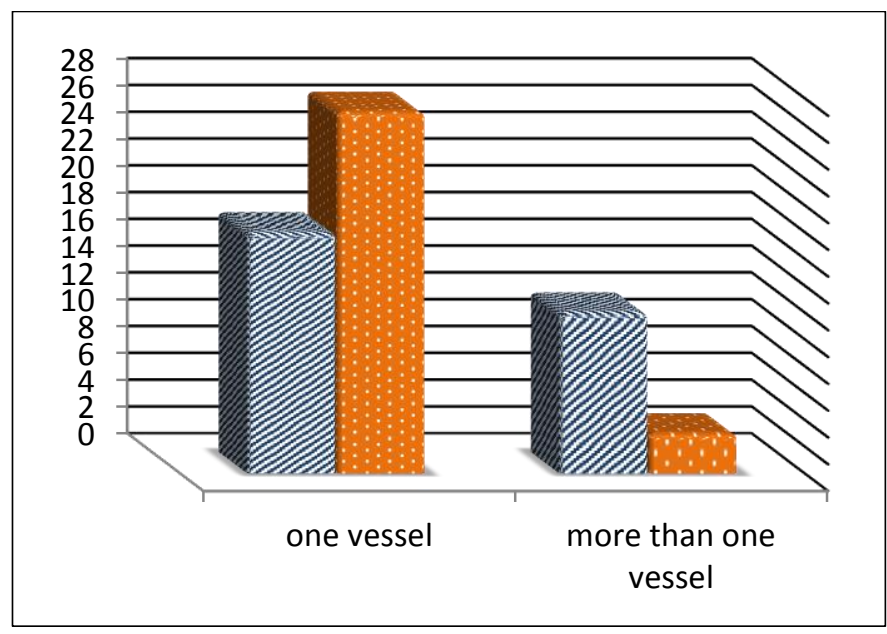

Figure (8): Number of diseased vessels in patients with and without mitral regurgitation

\section{DISCUSSION}

Mitral regurgitation is known to be a frequent complication of AMI. When present, it may exhibit a broad range of severity, from clinically evident and hemodynamically obvious to clinically silent and detected only as an incidental finding on catheterization or Doppler echocardiography ${ }^{(11)}$.

Papillary muscle dysfunction and associated dysfunction of the underlying ventricular wall are thought to be the most common cause of MR in postAMI patients ${ }^{(\mathbf{1 2})}$.

Although MR may place an additional hemodynamic stress on the LV, its prognostic significance independent of LV function has been controversial. Tcheng and his co-workers ${ }^{(12)}$ found that MR present on left ventriculography within 7 hours of MI was an independent predictor of survival at 1 year. They also found that moderately severe to severe MR appeared to be a likely independent predictor of impaired survival.

The current prospective study was designed to assess the prognosis of patients presenting with acute inferior STEMI who have ischemic mitral regurgitation compared to those who do not have ischemic mitral regurgitation and to compare the effect of PCI versus thrombolytic therapy on the short-term follow up of these patients in three months duration.

Population characteristics, clinical data, and risk factors for coronary artery disease were comparable between the two groups.
In or current study, we found that the difference between the two groups (group A versus group B) regarding both LVESD and LVEDD was statistically non-significant on admission (P-value was 0.083 and 0.083 respectively), however, this difference becomes statistically significant between both groups before discharge and on 3 months follow-up echo (P-value was 0.037 and $<0.001$ respectively). Our results are in concordance with Živile et al. ${ }^{(13)}$, who found a graded association between MR grade, LVEDD, and EF. Increasing LVEDD dimensions and decreasing EF are strongly associated with greater MR and thus greater in-hospital complications of these patients.

Chua et al. ${ }^{(11)}$ also found that factors associated with a significantly higher risk of positive IMR included increased LVES volume, LVED volume, and isolated inferior myocardial infarction. Enlarged LVES and LVED volumes are thought to indicate ventricular remodeling, in which the posterior papillary muscle that tethers the mitral valve is displaced, preventing leaflet closure and thus resulting in IMR.

In our current study, comparing EF and WMSI between the two groups, they were statistically nonsignificant on admission (P-value was > 0.05), however this difference becomes statistically significant before discharge (P-value was < 0.05$)$ and at 3 months follow-up (P-value was $<0.001$ ).

Živile et $\boldsymbol{a l} .{ }^{(13)}$ also found that low EF is an independent predictor for development of ischemic mitral regurgitation in patients with acute STEMI together with age, atrial fibrillation and higher LVEDD. Our data is concordant with a recent registry by López-Pérez et al. ${ }^{(14)}$, who found that moderate or severe MR detected early with echocardiography was independently associated with a worse long-term prognosis regarding $\mathrm{EF}$ and regional wall motion score index in patients with STEMI.

Our current study has found that the IMR group (group A) is associated with more complications regarding fatal arrhythmias, cardiogenic shock and reinfarction than the non-IMR group (group B). Heart failure was significantly more prevalent in group A patients than group B. (P-value was 0.021). Our study is in agreement with Chua et al. ${ }^{(11)}$, who attributed the development of heart failure after acute myocardial infarction to the loss of functioning myocytes, development of myocardial fibrosis, and subsequent LV remodeling, the ensuing chamber dilatation and neurohormonal activation leading to progressive LV dysfunction. The presence of IMR further inflicts the hemodynamic load during a period of active LV remodeling.

In our current study, subgroup analysis of group A regarding mitral regurgitation severity and jet area revealed that although there was a statistically nonsignificant difference between the two subgroups 
regarding mitral regurgitation jet area on admission, this difference become statistically significant before discharge and much more significant at 3 moths follow-up (P-value was <0.001). Similar to our results Chua et al. ${ }^{(11)}$ found that PCI for first acute STEMI was associated with a decreased incidence of IMR compared to a medically managed group. Early, rapid coronary revascularization with PCI was strongly associated with a significant risk reduction for having moderate or severe IMR by $14.6 \%$.

In our current study, comparing the two subgroups regarding other echocardiographic parameters including LVEF and WMSI, revealed that there was a significant improvement in these parameters in the PCI-subgroup compared to the thrombolytic subgroup (P-value was $>0.05$ on admission then became $<0.001$ at 3 months follow-up). In concordance with our results, Dzavík (15) concluded that restoration of coronary patency of totally occluded coronary arteries by PCI is associated with a significant improvement in regional and global left ventricular function, especially in patients with recent occlusions and depressed left ventricular function.

In our study, comparing the two subgroups as regarding the clinical outcomes, it was noticed that there was a relatively comparable in-hospital complications in the 2 subgroups regarding fatal arrhythmias, re-infarction, massive bleeding cardiogenic shock or mortality. However, the PCI subgroup (subgroup AI) had significantly fewer patients with decompensated heart failure on the follow-up period compared to the thrombolytic subgroup (subgroup AII). Generally primary PCI of the infarct related artery is preferred to fibrinolytic therapy in preserving $\mathrm{LV}$ function and reducing the incidence of clinically significant decompensated heart failure especially when time-to-treatment delays are short with door to balloon time less than 120 minutes and the patient presents to a high-volume, well-equipped center with experienced interventional cardiologists and skilled support staff (16).

Compared with fibrinolytic therapy, primary PCI produced higher rates of infarct artery patency, TIMI 3 flow, and access site bleeding and lower rates of recurrent ischemia, re-infarction, emergency repeat revascularization procedures, intracranial hemorrhage (ICH), and death ${ }^{(17)}$.

In our current study, comparing the two PCI groups (subgroup AI versus B) showed that the incidence of MR was higher in patients with more extensive coronary artery disease (more than one vessel disease). This is in concordance with a recent study by Živilè $\boldsymbol{e t}$ al. ${ }^{(13)}$, who found that number of coronary vessels with angiographically significant lesions (coronary artery luminal stenosis by visual assessment equal to or greater than 70\%) was higher in IMR group compared to the non-IMR group. Patients with IMR more likely had triple vessel disease compared to the non-IMR group. Left main coronary artery and right coronary artery disease were strongly associated with the development of IMR ${ }^{(14)}$.

\section{CONCLUSION}

Patients with inferior myocardial infarction who develop ischemic mitral regurgitation are at higher risk for developing major adverse cardiovascular complications, namely cardiogenic shock, malignant arrhythmias, re-infarction, congestive heart failure and death. Primary PCI in these patients will markedly reduce the risk for developing these complications compared to fibrinolytic therapy.

\section{RECOMMENDATION}

- Based on the results of our study, close monitoring of patients developing ischemic mitral regurgitation in the setting of acute coronary syndrome is recommended.

- Development of ischemic mitral regurgitation increase the risk of multivessel coronary artery disease of these patients.

- Patients with ischemic mitral regurgitation will benefit mostly from early invasive strategy in treatment. Primary PCI should be recommended for these patients whenever feasible.

\section{REFERENCES}

1- Levine RA, Schwammenthal E (2005): Ischemic mitral regurgitation on the threshold of a solution: from paradoxes to unifying concepts. Circulation, 112: 745758.

2- Pellizzon GG, Grines CL, Cox DA et al. (2004): Importance of mitral regurgitation in patients undergoing percutaneous coronaryintervention for acute myocardial infarction: The Controlled Abciximab and Device Investigation to Lower Late Angioplasty Complications (CADILLAC) trial. J Am Coll Cardiol., 43: 1368-1374.

3- Grigioni F, Enriquez-Sarano M, Zehr KJ et al. (2001): Ischemic mitral regurgitation: long-term outcome and prognostic implications with quantitative Doppler assessment. Circulation, 103: 1759-64.

4- Ellis SG, Whitlow PL, Raymond RE et al. (2002): Impact of mitral regurgitation on long-term survival after percutaneous coronary intervention. Am J Cardiol., 89: 315-318.

5- Grossi EA, Woo YJ, Schwartz CF et al. (2006): Comparison of Coapsysannuloplasty and internal reduction mitral annuloplasty in the randomized treatment of functional ischemic mitral regurgitation: impact on the left ventricle. J Thorac Cardiovasc Surg, 131: 1095-8.

6- Aaronson KD, Bolling SF, WU HO et al. (2005): Impact of mitral valve annuloplasty on mortality risk in patients with mitral regurgitation and left ventricular systolic dysfunction. J Am Coll Cardiol., 45: 381-7.

7- Benjamin M, Jackson M (2003): Annuloplasty ring selection for chronic ischemic mitral regurgitation: 
lessons from the ovine model. Ann Thorac Surg., 87: 1556-1563.

8- Cannon CP, Sabatine MS, Gibson CM et al. (2005): Addition of clopidogrel to aspirin and fibrinolytic therapy for myocardial infarction with STsegment elevation. N Engl J Med., 352: 1179-1189.

9- Grigioni F, Detaint D, Avierinos J et al. (2005): Contribution of ischemic mitral regurgitation to congestive heart failure after myocardial infarction. J Am Coll Cardiol., 45: 260-267.

10- Thygesen K, Alpert J, Jaffe A et al. (2012): Third universal definition of acute myocardial infarction. European Heart Journal, 33: 2551- 2567

11- Chua S, Hung J, Chung SY et al. (2010): Primary Percutaneous Coronary Intervention Lowers the Incidence of Ischemic Mitral Regurgitation in Patients With Acute ST-Elevated Myocardial Infarction. Circ J., 74: 2386-2392.

12- Tcheng JE, Puma JA, Sketch MH et al. (2010): Percutaneous revascularization of chronic coronary occlusion: an overview. J Am Coll Cardiol., 26: 111116.
13- Živilè V, Dominyka U and Renaldas J (2015): Functional (ischemic) mitral regurgitation in acute phase of myocardial infarction: Associated clinical factors and in-hospital outcomes. Medicina, 51: 92-99.

14- López-Pérez M, Estévez-Loureiro R, López-Sainz A et al. (2014): Long-Term Prognostic Value of Mitral Regurgitation in Patients With STSegment Elevation Myocardial Infarction Treated by Primary Percutaneous Coronary Intervention. Am J Cardiol., 113: 907-912.

15- Dzavík V (2006): The Total Occlusion Study of Canada (TOSCA)-2 trial. Circulation, 114: 2449-57.

16- O'Gara PT, Kushner FG, Ascheim DD et al. (2013): 2013 ACCF/AHA guideline for the management of ST-Elevation myocardial infarction: A report of the American College of Cardiology Foundation/American Heart Association task force on practice guidelines. Circulation, 127: 362-425.

17- Keeley EC, Hillis LD (1996): Left ventricular mural thrombus after acute myocardial infarction. Clin Cardiol., 19: 83-86. 